\title{
IJNVSM Special Edition: Sustainable and Responsible Consumption: Evidences from Emerging Economies
}

Welcome to this special issue, which includes nine papers that collectively seek to understand the sustainable and responsible consumption in emerging economies. While the authors have sought to address sustainability from various perspectives, such as organic food, electric vehicles, sustainable commuting, shared clothing, and reconstructed products, they share the prevailing view about the importance of sustainable consumption.

Environmental issues have become a topic of interest at the global level. Researchers and practitioners in the field of business management have recently paid increased attention to the concept of sustainability. However, the best way to enhance sustainability in society is to encourage individuals to adopt eco-friendly activities in their day-to-day life (Prothero et al., 2011). An individual's consumption patterns affect the environment, the functioning of the ecosystem, and the availability of resources (Connolly \& Prothero, 2003). It is, therefore, believed that sustainability and environmental consciousness should be incorporated into an individual's consumer behavior. Sustainable and responsible consumption will also contribute to economic development. While several studies have focused on sustainable consumption in developed countries, only very few studies have investigated it in emerging economies (Khare, 2015). According to Yadav et al. (2016), about 90 percent of studies in the area of socially conscious consumerism is limited to developed regions of Europe and North America. Although a large proportion of the global population resides in emerging economies, environmental consciousness among the people living in these parts of the world is limited (Scott \&Vigar-Ellis, 2014). Emerging economies tend to take initiatives to respond to the environmental problems and to enhance sustainability (Vergragt, Akenji, \& DeWick, 2014; Yadav \& Pathak, 2017); however, very limited 
emphasis has been placed on individuals' commitment to adopting sustainability and their sustainability practices in their consumption behaviors (Yadav, Dokania, \& Pathak, 2016). Considering this, the special issue emphasises sustainable and responsible consumption in the context of emerging economies.

The first paper, "Motivators and barriers to sustainable food consumption: Qualitative inquiry about organic food consumers in a developing nation" by Rambalak Yadav, Pankaj Kumar Singh, Ankur Srivastava, and Anees Ahmad, identifies the motivators and barriers of organic food consumption in the Indian context. A grounded theory approach demonstrated the motivators that trigger the purchase of organic food, namely, health consciousness, environmental consciousness, social identity, consumer ethnocentrism, and concern for farmers. Moreover, the factors viz. high prices of organic food, unavailability, trust issues, and limited marketing communications by the firms, are ascertained as the barriers to the consumption of organic food.

The second paper titled "Marketing Challenges and Organic Farming in India—Does Farm Size Matter?" by Sikandar Azam, Musarrat Shaheen, and Sonali Narbariya highlights the marketing challenges of farmers who are involved in organic farming in India. Organic food is sustainable food, and organic farming encourages responsible consumption. The authors explore various marketing challenges that influence the intentions to adopt organic farming. They investigate the challenges according to different farm sizes. The findings are useful in addressing the challenges the farmers face in organic farming in an emerging economy like India. 
The third paper titled "A Theories of Practice Perspective in Understanding Barriers to Sustainable Commuting: The Case of UAE" authored by Shilpa Iyanna, Carmela Bosangit, Jordon Lazell, and Marylyn Carrigan investigates a range of elements that collectively shape the practices of daily commuting. The authors have used a qualitative approach to understand sustainable commuting among residents in the UAE. The research also showed insights into barriers to sustainable commuting and outlines viable opportunities to provide sustainable commuting.

The fourth paper titled "Factors explaining shared clothes consumption in China: Individual benefits or planet concern" authored by Jashim Khan and Sharyn Rundle-Thiele is aimed at expanding the understanding of the consumption of shared clothes with the underpinnings of attitude-intention behavior theory. A total of 250 responses from current users and 232 responses from potential users was gathered using surveys. The findings showed that environmental concerns are higher among current users than potential users of the shared clothing platform. The results also demonstrate that personal considerations, such as economic benefits outweigh environmental considerations when it comes to the consumption of shared clothing.

The next paper is by Jighyasu Gaur, Ritu Gupta, Pratyush Banerjee, and Mehdi Amini, entitled, “Influence of cultural divergence on consumers' perception towards reconstructed products: A qualitative inquiry." The paper is aimed at understanding whether consumers from different cultures have varied perceptions of reconstructed products. The authors took theoretical support from the cultural divergence concept and collected data from the consumers of two culturally diverse societies: India and the USA. The grounded theory approach was used for interviews and data analysis. Culture, being one of the critical findings of the study, plays a decisive role in shaping consumers' perceptions of reconstructed products. However, other factors, i.e., 
product/process-related factors, brand/store-related factors, and individual factors, also influence these perceptions.

The next paper authored by Amit Shankar and Puja Kumari attempted to investigate the enablers and inhibitors of electric vehicles (EV) adoption intention from the sellers' perspective using a dual-factor model. The researchers have used an extended TPB framework to explore the enablers, whereas the status quo bias theory has been used to explore the inhibitors of EV adoption. The results indicate that attitude, subjective norm, perceived behavioral control, environmental concern, and perceived CSR obligations have a significant positive impact on the intention to adopt EVs. However, regret avoidance, inertia, perceived threat, and perceived value have significant impacts on the resistance to adopt EVs. This study enriches the literature on green technology adoption and provides several suggestions to marketers for increasing the pace of EV adoption.

The next paper in the issue is "Modelling the Predictors of Young Consumers' Sustainable Consumption Intention" authored by Yatish Joshi, Deepak Sangroya, Anugamini Priya Srivastava, and Mayank Yadav. This research paper attempts to explore the various determinants of sustainable consumption intentions. Based on the theory of planned behavior and the theory of reciprocal determinism, the findings show that past sustainable experience and environmental responsibility affect consumers' sustainable intentions. The study offers a different approach to develop consumers' sustainable consumption behaviors and provides an applicable model to determine sustainable consumption intention. 
The next paper ttitled "What drives organic food consumption in Lebanon?" was authored by Malak Tlies, Roberta Callieris, Lina Al Bitar, Rocco Roma and John Thøgersen. Hierarchal value maps constructed from the laddering interviews showed that "quality of life," "pleasure," and "peace of mind" are the main values driving organic food consumption in Lebanon. Frequent organic consumers displayed higher concerns for their family's health and for environment, whereas occasional organic consumers cared more for their own pleasure and were more likely to perceive organic food as a traditional and nostalgic product.

The final paper in the special issue titled "Answering Key Questions on Green Consumption: A Qualitative Study among Indian Youth" by Manish Gupta and Anitha Acharya is aimed at comprehending the meaning of green consumption, identifying the products that are considered green by Indian youth, exploring the reasons behind green product consumption, and deciphering the possible implications of consuming green. The authors' core argument is that the past literature does not provide a comprehensive and clear definition of green consumption and that very few studies cover this concept in the context of Indian youth. The authors conducted a qualitative study by interviewing information-rich cases. Based on the responses, they developed thematic maps and identified three significant themes, namely (1) personal factors, (2) social factors, and (3) environmental factors. Based on the thematic analysis, they also propose a model of green consumption.

Finally, the guest editors would like to sincerely thank all the reviewers who helped us with reviewing and re-reviewing manuscripts. We would also like to appreciate the continuous guidance and support from Jane Hudson, the Editor in Chief of International Journal of Nonprofit and Voluntary Sector Marketing, for this special issue. 


\section{References}

Connolly, J., \& Prothero, A. (2003). Sustainable consumption: consumption, consumers and the commodity discourse. Consumption, Markets and Culture, 6(4), 275-291.

Cotte, J., \& Trudel, R. (2010). Socially conscious consumerism: A systematic review of the body of knowledge. Network for Business Sustainability, Available at https://www.nbs.net/articles/systematic-review-socially-conscious-consumerism

Jakovcevic, A., Steg, L., Mazzeo, N., Caballero, R., Franco, P., Putrino, N., \& Favara, J. (2014). Charges for plastic bags: Motivational and behavioral effects. Journal of Environmental Psychology, 40, 372-380.

Khare, A. (2015). Antecedents to green buying behaviour: a study on consumers in an emerging economy. Marketing Intelligence \& Planning, 33(3), 309-329.

Prothero, A., Dobscha, S., Freund, J., Kilbourne, W. E., Luchs, M. G., Ozanne, L. K., \& Thøgersen, J. (2011). Sustainable consumption: Opportunities for consumer research and public policy. Journal of Public Policy \& Marketing, 30(1), 31-38.

Scott, L., \& Vigar-Ellis, D. (2014). Consumer understanding, perceptions and behaviours with regard to environmentally friendly packaging in a developing nation. International Journal of Consumer Studies, 38(6), 642-649.

Vergragt, P., Akenji, L., \& Dewick, P. (2014). Sustainable production, consumption, and livelihoods: global and regional research perspectives. Journal of Cleaner Production, 63, 1-12.

Yadav, R., \& Pathak, G. S. (2017). Determinants of consumers' green purchase behavior in a developing nation: Applying and extending the theory of planned behavior. Ecological Economics, $134,114-122$.

Yadav, R., Kumar Dokania, A., \& Swaroop Pathak, G. (2016). The influence of green marketing functions in building corporate image: Evidences from hospitality industry in a developing nation. International Journal of Contemporary Hospitality Management, 28(10), 2178-2196. 